\title{
Quantification of Rapid Eye Movement Sleep without Atonia to Diagnose Rapid Eye Movement Sleep Behavior Disorder: A Retrospective and Case-Control Study
}

\author{
Jiyoung Kim ${ }^{1,2}$, Gha-Hyun Lee ${ }^{1}$, Sang Min Sung ${ }^{1}$, Taewoong Kim², Dae Soo Jung ${ }^{1}$ \\ ${ }^{1}$ Department of Neurology, Pusan National University School of Medicine, Busan, \\ ${ }^{2}$ Sleep Disorders Center, Pusan National University Hospital, Busan, Korea
}

\author{
렘수면행동장애 진단을 위한 렘수면무긴장소실의 정량적 분석: 후향적 환자-대조군 연구 \\ 김지영 ${ }^{1,2}$, 이가현 ${ }^{1}$, 성상민 $^{1}$, 김태웅 ${ }^{2}$, 정대수 ${ }^{1}$

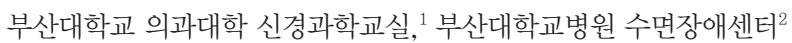

Received December 13,2019 Revised February 11, 2020 Accepted February 24, 2020

Address for correspondence Dae Soo Jung, MD, PhD Department of Neurology,

Pusan National University

School of Medicine,

179 Gudeok-ro, Seo-gu,

Busan 49241, Korea

Tel: +82-51-240-7311

Fax: +82-51-254-7317

E-mail: jungds@pusan.ac.kr
Objectives: Rapid eye movement (REM) sleep without atonia (RSWA) fulfils one of the criteria for diagnosing REM sleep behavior disorder (RBD) according to the International Classification of Sleep Disorders, Third Edition. However, RSWA quantification is an unresolved issue, which is associated with the future direction of revising the diagnostic criteria. The purpose of this study was to evaluate the quantification of RSWA in patients with RBD and identify an optimal cut-off value of quantitative RSWA for RBD diagnosis. Methods: Medical records and polysomnographic results were analyzed retrospectively to diagnose sleep disorders from June 2017 to May 2018 at Pusan National University Hospital. Nineteen subjects with idiopathic RBD were included in the present study. Propensity score matching was used to control age, gender, and anti-depressant factors, which influenced RSWA. RSWA was scored according to the American Academy of Sleep Medicine scoring manual. Cohen's kappa coefficient was measured to test inter-rater reliability between two polysomnography raters. Results: Cohen's kappa coefficients were $0.755(p<0.001)$ and 0.689 $(p<0.001)$ for tonic and phasic activities, respectively. RSWA was significantly increased in subjects with RBD compared with controls [median and interquartile range: 16.5 (8.8-24.6) vs. $6.3(4.1-7.2) p=0.001$ ]. The optimal cut-off value was $8.0 \%$ for the proportion of RSWA (sensitivity $78.5 \%$, specificity $85.7 \%$, area under the receiver-operating characteristic curve 0.837). Conclusions: Subjects with RBD had significantly increased RSWA compared to controls. The proportion of RSWA during REM sleep can be applied to discriminate subjects with RBD from controls.

J Sleep Med 2020;17(1):31-36

\section{서 론}

렘수면행동장애[rapid eye movement(REM) sleep behavior disorder]는 사건수면 중 하나로 렘수면(REM sleep) 시 기에 근육의 무긴장(atonia)이 소실되고, 비정상적인 행동 및 움직임을 보이는 질환이다. 렘수면행동장애 증상은 1965년 다리뇌 덮개(pontine tegmentum) 부위에 병변이 있는 고양

This is an Open Access article distributed under the terms of the Creative Commons Attribution Non-Commercial License (https://creativecommons.org/licenses/by-nc/4.0) which permits unrestricted non-commercial use, distribution, and reproduction in any medium, provided the original work is properly cited.
이에서 먼저 보고되었으며, ${ }^{2}$ 사람에서는 1986년 처음으로 보 고되었다. ${ }^{3}$ 일반 인구 집단을 대상으로 한 연구에서 유병률 은 0.38 0.45\%로 알려져 있으며, 4.5 렘수면행동장애에서 관 찰되는 렘수면무긴장소실(REM sleep without atonia)의 병 리기전은 보행중추(locomotor generators) 활동증가 및 sublaterodorsal nucleus 회로(circuit)의 장애로 생각하고 있다. ${ }^{6}$ 1995년 렘수면행동장애를 보인 환자의 부검 소견에서 루이 소체가 우연히 확인되었고, 최근에는 알파-시누클레인병증 ( $\alpha$-synucleinopathy)을 포함한 신경퇴행성 질환과 렘수면행 동장애가 밀접하게 관련된다고 보고되고 있다.,8 최근 보고 
된 메타분석에서는 렘수면행동장애 환자를 평균 4.75년간 추적을 한 경우 $31.95 \%$ 에서 파킨슨병, 다기관위축증, 루이 소체치매, 경도인지장애를 포함한 신경퇴행성 질환을 보였 고, 장기간 추적의 경우 $90 \%$ 이상에서 신경퇴행성 질환을 보 일 것으로 평가하였다. ${ }^{9}$

국제수면질환분류 3판(International Classification of Sleep Disorders, Third Edition)은 렘수면행동장애 진단 기준 중 하나로 수면다원검사 시 렘수면무긴장소실을 제시하고 있 다. 렘수면행동장애에서 렘수면무긴장소실에 대한 체계적인 정의와 정량화는 1992년 Lapierre와 Montplaisir에 의해 처 음으로 시도되었다. ${ }^{10}$ 그러나 렘수면무긴장소실 정량화는 지 난 20년간 여러 연구자들에 의해 진행되었음에도, 렘수면행 동장애 진단을 위한 렘수면무긴장소실의 판정 기준값에 대 한 일치된 의견은 아직 없다. ${ }^{11}$ 이는 연구자마다 렘수면무긴 장소실에 대한 다른 판단 기준과 다양한 부위의 근전도를 사용해서 평가했기 때문이다. 국제수면질환분류 3판에서도 “렘수면무긴장소실에 대한 기준은 최신의 미국수면의학회 (American Academy of Sleep Medicine)의 수면다원검사 채점 기준에 따른다."라고만 기술되어 있고, 무긴장의 소실과 관련된 정량적 기준은 제시하지 못하고 있다. 즉 렘수면 중 발생하는 무긴장의 소실 비율이 어느 정도 있어야 렘수면행 동장애를 진단하고, 렘수면행동장애를 배제할 수 있는가에 대한 기준을 제시하지 못하고 있다. ${ }^{1}$ 따라서 본 연구는 렘수 면행동장애군과 비렘수면행동장애군 사이에서 렘수면무긴 장소실을 정량화하고 비교하여 렘수면행동장애 진단을 위 한 렘수면무긴장소실의 판정 기준값을 제시하기 위해 실시 되었다.

\section{방 법}

\section{대 상}

렘수면행동장애군과 대조군은 2017년 6월부터 2018년 5월 사이 수면장애를 주 증상으로 하여 부산대학교병원 신경과 를 방문하여 수면다원검사를 실시한 이들을 대상으로 하였 다. 렘수면행동장애군은 사건수면을 주 증상으로 방문하여 병력 및 수면다원검사 결과를 바탕으로 하여 렘수면행동장 애가 진단된 이들로 하였다. 이차적인 사건수면 및 렘수면행 동장애를 배제하기 위하여 기면병이 진단되었거나, 알츠하 이머 치매로 진료 중이거나, 신체검사에서 파킨슨 증후군으 로 판단되는 경우는 제외하였다. 대조군은 병력에서 사건수 면이 없으며, 코골이 및 무호흡을 주 증상으로 방문하여 수 면다원검사에서 시간당 무호흡-저호흡지수가 $30 / \mathrm{hr}$ 미만으 로 확인된 경우로 하였다. 대조군 역시 기면병이 진단되었거
나, 알츠하이머 치매로 진료 중이거나, 신체검사에서 파킨슨 증후군으로 판단되는 경우는 제외하였다. 또한 해당 기간에 환자군 및 대조군에 포함된 이들을 대상으로 하여 선택 편견 을 줄이기 위하여 성향점수를 이용한 환자군-대조군 짝짓 기를 실시하였다. 성향점수 짝짓기는 나이, 성별 및 렘수면 행동장애의 유발 요인으로 알려져 있는 선택적 세로토닌 재 흡수 억제제(selective serotonin reuptake inhibitors) 사용 여 부를 공변량으로 실시하였다. ${ }^{12}$ 성향점수를 이용한 짝짓기 전 렘수면행동장애군은 19 명, 대조군은 23명이었고, 짝짓기 후 렘수면행동장애군 및 대조군은 각각 14 명이었다. 본 연구는 부산대학교병원 기관생명윤리위원회의 승인하에 이루어졌 다(1908-017-082).

\section{야간 수면다원검사}

수면다원검사(COMET PSG, Grass Technology, Warwick, RI, USA)는 표준뇌파(F4-M1, C4-M1, O2-M1, F3-M2, C3-M2, O1-M2), 무호흡, 저호흡, 호흡노력, 안전도, 턱 및 앞쪽 정강근육 근전도, 심전도, 산소포화도, 코골이 및 체위 를 측정하였다. 또한 수면다원검사 시 비디오 모니터링을 통 해서 수면 중 나타나는 신체 움직임에 대해서도 기록하였다. 수면다원검사의 결과 분석은 미국수면학회의 평가 기준에 따라 실시하였다.

\section{렘수면무긴장소실}

렘수면무긴장소실은 렘수면 시 나타나는 긴장성 움직임 (tonic activity)은 턱근전도에서 위상성 움직임(phasic activity)은 턱근전도 및 하지근전도에서 평가하였다. ${ }^{13}$ 긴장성 움 직임은 렘수면 시 턱근전도에서 기존 수면 근전도 소견에 비 하여 4배 이상 큰 진폭이 한 에포크 절반 이상에서 확인된 경 우로 정의하였다. ${ }^{14,15}$ 위상성 움직임은 턱 및 앞쪽 정강근육 에서 측정된 근전도에서 한 에포크를 10 개로 나눈 3 초 단위 의 미니 에포크에서, 기존 수면 근전도에 비하여 4 배 이상 진 폭이 증가된 근전도 소견이 0.1 5초 동안 존재하는 미니 에 포크가 5개 이상일 때로 정의하였다. ${ }^{14,15}$ 수면다원검사 시 턱 근전도와 앞쪽 정강근육에서 확인된 긴장성 움직임 및 위상 성 움직임의 정량화는 에포크 단위로 구분하여 평가하였다. 따라서 긴장성 움직임, 위상성 움직임 및 이를 합산하여 구 한 전체 렘수면무긴장소실의 정도는 수면다원검사 시 기록 된 렘수면 에포크에 대한 비율로 표시하였다. ${ }^{15}$ 또한 렘수면 무긴장소실 판단은 두 명의 평가자가 각각 독립적으로 평가 하여 실시하였다. 렘수면무긴장소실을 구하기에 앞서 두 평 가자 간에 렘수면무긴장소실 평가에 대한 신뢰도를 확인하 기 위하여 무작위로 렘수면행동장애군 1 명과 대조군 1 명을 
선택하여 일치도를 평가하였다. 두 평가자 사이의 일치도 정 도를 평가하기 위해 확인한 Cohen's kappa 계수는 긴장성 움직임에 대해서는 $0.755(p<0.001)$, 위상성 움직임에 대해서 는 $0.689(p<0.001)$ 를 보여 두 평가자 사이에 상당한 일치도 를 확인 후 렘수면무긴장소실에 대한 평가를 진행하였다. ${ }^{16}$

\section{자료 분석}

렘수면행동장애군과 대조군의 비교를 위하여 연속형 변수 는 정규성을 확인 후, 정규성을 따르는 경우 독립 표본 $\mathrm{T}$ 검 정(independent T-test)을 실시하였고, 정규성을 따르지 않는 경우 맨-휘트니 U 검정(Mann-Whitney U test)을 실시하였 다. 비연속형 변수의 경우 카이제곱 검정법(chi-square test) 혹은 피셔의 정확 검정(Fisher's exact test)을 실시하였다. 실 험군과 대조군의 짝짓기는 최소 거리법을 이용한 $1: 1$ 짝짓기 를 이용한 성향점수 매칭(propensity score matching)을 이용 하였다. 통계 분석에는 SPSS version 22.0(IBM Corp., Armonk, NY, USA)을 이용하였으며, 통계적 유의성은 양측 검 정하에 $p$ 값이 0.05 미만일 때 통계적으로 유의한 것으로 판 단하였다. 또한 렘수면행동장애군 진단을 위한 렘수면무긴 장의 절단값(cut-off)을 제시하기 위하여 receiver operating characteristic(ROC) 커브를 구하였고, 그 커브에서 area under the curve가 최대가 되는 수치를 절단값으로 제시하였다. 절단값의 제시는 MedCalc version 19.0.7(MedCalc Software bvba, Ostend, Belgium) 프로그램을 이용하였다.

\section{결 과}

\section{인구 통계학적 특징 및 수면다원검사 결과 비교}

본 연구에는 propensity score를 이용한 짝짓기 전 렘수면 행동장애군에는 총 19 명, 대조군에는 23명이 포함되었고, 짝 짓기 이후에는 렘수면행동장애군에 14 명, 대조군에 14 명이
각각 포함되었다. 짝짓기 후 렘수면행동장애군과 대조군의 비교에서 렘수면행동장애군에 비하여 대조군에서 주간 졸림 정도를 나타내는 Epworth sleepiness scale이 유의하게 증가 하였다(Table 1). 또한 수면다원검사 결과에서는 짝짓기 전 총 수면 시간(total sleep time)이 렘수면행동장애군이 증가 되어 있었으나, 짝짓기 이후에는 두 군 간에 총 수면 시간은 유의한 차이를 보이지 않았다(Table 2).

\section{렘수면무긴장소실의 정량적 비교}

수면다원검사에서 확인된 렘수면무긴장소실의 정도는 짝 짓기 이후 렘수면행동장애군에서는 중위값이 $16.5 \%$ (평균 표준편차, $20.8 \pm 16.5$ ), 대조군에서는 $6.3 \%$ (평균 \pm 표준편차, $6.0 \pm 3.6$ )를 보여 두 군에서 유의한 차이를 보이고 있었다. 또 한 긴장성 움직임 및 위상성 움직임에서도 렘수면행동장애 군과 대조군은 유의한 차이를 보이고 있었다(Table 3).

\section{렘수면무긴장소실의 판정 기준값}

렘수면행동장애군과 대조군을 구분 짓기 위한 판정 기준 값을 구하기 위하여 짝짓기 이후 렘수면무긴장소실의 분포 에 해당하는 ROC 곡선을 작성하였다. 두 군을 나누는 판정 기준값은 $8.0 \%$ (곡선 아래 면적 0.837 , 민감도 $78.5 \%$, 특이도 $85.7 \%$ )였다(Fig. 1). 또한 긴장성 움직임에서는 $4.9 \%$ (곡선 아래 면적 0.855 , 민감도 $78.6 \%$, 특이도 $85.7 \%)$, 위상성 움직 임에서는 $4.2 \%$ (곡선 아래 면적 0.709 , 민감도 $50.0 \%$, 특이도 92.8\%)였다(Fig. 2, 3).

\section{고 찰}

본 연구는 렘수면행동장애의 진단 기준 중 하나인 렘수면 무긴장소실을 정량화하고, 렘수면무긴장소실의 판정 기준값 을 평가하기 위하여 실시되었다. 렘수면행동장애군의 렘수

Table 1. Baseline demographics and general characteristics of participants

\begin{tabular}{|c|c|c|c|c|c|c|}
\hline \multirow{2}{*}{ Variables } & \multicolumn{3}{|c|}{ Total data set } & \multicolumn{3}{|c|}{ Data set by PSM } \\
\hline & RBD (n=19) & Controls $(n=23)$ & $p$ & $\mathrm{RBD}(\mathrm{n}=14)$ & Controls $(\mathrm{n}=14)$ & $p$ \\
\hline Age*, yr & $61.0(56.0-65.0)$ & $60.0(54.0-64.0)$ & 0.551 & $60.5(54.0-62.5)$ & $61.0(52.5-65.3)$ & 0.729 \\
\hline Gender, male (\%) & $8(42.1)$ & $12(52.2)$ & 0.516 & $7(50.0)$ & $7(50.0)$ & 1.00 \\
\hline $\mathrm{BMI}^{*}, \mathrm{~kg} / \mathrm{m}^{2}$ & $24.4 \pm 3.1$ & $23.3 \pm 2.3$ & 0.192 & $23.9 \pm 2.8$ & $22.7 \pm 2.1$ & 0.193 \\
\hline ESS* & $5.0(2.0-8.0)$ & $7.0(3.0-12.0)$ & 0.200 & $5.5(2.0-8.0)$ & $9.0(6.0-14.0)$ & 0.037 \\
\hline BDI & $9.6 \pm 5.4$ & $9.1 \pm 7.9$ & 0.799 & $9.1 \pm 4.7$ & $10.6 \pm 9.2$ & 0.591 \\
\hline PSQI & $9.6 \pm 4.0$ & $8.3 \pm 4.2$ & 0.306 & $9.1 \pm 4.1$ & $8.4 \pm 4.7$ & 0.672 \\
\hline SSRI & $4(21.1)$ & $5(21.7)$ & 1.00 & $2(14.3)$ & $4(28.6)$ & 0.648 \\
\hline
\end{tabular}

*variables are analyzed by Mann-Whitney $U$ test and shown as a median (interquartile range). PSM: propensity score matching, RBD: rapid eye movement sleep behavior disorder, BMI: body mass index, ESS: Epworth sleepiness scale, BDI: Beck depression inventory, PSQI: Pittsburgh sleep quality index, SSRI: selective serotonin reuptake inhibitor 
Table 2. Comparison of polysomnographics results between RBD and controls

\begin{tabular}{|c|c|c|c|c|c|c|}
\hline \multirow{2}{*}{ Variables } & \multicolumn{3}{|c|}{ Total data set } & \multicolumn{3}{|c|}{ Data set by PSM } \\
\hline & RBD (n=19) & Controls $(\mathrm{n}=23)$ & $p$ & $\mathrm{RBD}(\mathrm{n}=14)$ & Controls $(\mathrm{n}=14)$ & $p$ \\
\hline Total sleep, min & $368.0 \pm 55.2$ & $328.4 \pm 78.0$ & 0.043 & $359.1 \pm 53.9$ & $333.6 \pm 80.9$ & 0.337 \\
\hline Sleep latency*, min & $4.5(1.5-11.0)$ & $5.5(3.0-9.5)$ & 0.411 & $4.0(1.4-7.1)$ & $4.5(2.4-8.6)$ & 0.645 \\
\hline REM latency*, min & $111.0(77.5-159.5)$ & $122.5(66.0-194.0)$ & 0.919 & $106.0(77.3-163.1)$ & $142.3(99.8-220.4)$ & 0.395 \\
\hline Sleep efficiency, \% & $81.4 \pm 10.3$ & $78.1 \pm 12.3$ & 0.361 & $79.7 \pm 10.7$ & $80.7 \pm 10.8$ & 0.793 \\
\hline Arousal index, $/ \mathrm{hr}$ & $10.9 \pm 6.5$ & $12.7 \pm 7.2$ & 0.399 & $11.6 \pm 7.2$ & $14.8 \pm 6.7$ & 0.238 \\
\hline PLM index*, /hr & $2.4(0.0-31.8)$ & $0.0(0.0-18.5)$ & 0.320 & $2.2(0.0-33.4)$ & $0.0(0.0-18.7)$ & 0.238 \\
\hline Total AHI, /hr & $12.1 \pm 9.5$ & $14.1 \pm 10.7$ & 0.530 & $11.9 \pm 9.5$ & $15.4 \pm 11.8$ & 0.390 \\
\hline \multicolumn{7}{|l|}{ Sleep architecture, \% } \\
\hline $\mathrm{N} 1^{*}$ & $17.6(8.0-25.2)$ & $16.2(12.7-25.4)$ & 0.622 & $20.1(11.7-25.7)$ & $16.1(12.5-26.1)$ & 0.927 \\
\hline $\mathrm{N} 2 *$ & $61.6(50.5-66.0)$ & $57.0(51.0-66.0)$ & 0.511 & $60.4(50.3-67.2)$ & $58.8(48.8-70.6)$ & 0.800 \\
\hline N3* & $6.7(0.0-8.7)$ & $6.5(4.8-12.2)$ & 0.282 & $4.2(0.0-9.2)$ & $6.5(5.3-8.4)$ & 0.249 \\
\hline $\mathrm{REM}^{*}$ & $14.8(8.9-21.2)$ & $15.1(8.9-19.6)$ & 0.752 & $13.9(8.1-21.4)$ & $14.6(8.7-21.4)$ & 0.927 \\
\hline REM duration, min & $56.2 \pm 25.9$ & $49.8 \pm 22.3$ & 0.392 & $51.4 \pm 28.2$ & $49.9 \pm 27.7$ & 0.891 \\
\hline
\end{tabular}

*variables are analyzed by Mann-Whitney $U$ test and shown as a median (interquartile range). PSM: propensity score matching, RBD: REM sleep behavior disorder, REM: rapid eye movement, PLM: periodic limb movement, AHI: apnea-hypopnea index

Table 3. Comparison of RSWA proportion between RBD and controls

\begin{tabular}{|c|c|c|c|c|c|c|}
\hline \multirow{2}{*}{ Variables } & \multicolumn{3}{|c|}{ Total data set } & \multicolumn{3}{|c|}{ Data set by PSM } \\
\hline & $\mathrm{RBD}(\mathrm{n}=19)$ & Controls $(\mathrm{n}=23)$ & $p$ & $\operatorname{RBD}(\mathrm{n}=14)$ & Controls $(\mathrm{n}=14)$ & $p$ \\
\hline \multirow[t]{2}{*}{ Tonic activity*, \% } & $11.7(5.2-15.6)$ & $3.8(1.7-4.7)$ & $<0.001$ & $12.0(5.0-20.1)$ & $4.0(1.3-4.9)$ & 0.001 \\
\hline & $12.5 \pm 9.6$ & $3.6 \pm 2.6$ & & $14.2 \pm 10.4$ & $3.8 \pm 3.1$ & \\
\hline \multirow[t]{2}{*}{ Phasic activity*, \% } & $4.4(2.4-9.9)$ & $2.2(1.6-3.2)$ & 0.017 & $3.8(2.3-9.5)$ & $2.0(1.5-3.5)$ & 0.039 \\
\hline & $6.5 \pm 7.0$ & $2.5 \pm 1.1$ & & $6.7 \pm 7.9$ & $2.3 \pm 1.3$ & \\
\hline \multirow[t]{2}{*}{ RSWA*, \% } & $14.8(9.6-23.0)$ & $5.7(4.1-7.2)$ & $<0.001$ & $16.5(8.8-24.6)$ & $6.3(4.1-7.2)$ & 0.001 \\
\hline & $19.0 \pm 14.9$ & $5.9 \pm 2.8$ & & $20.8 \pm 16.5$ & $6.0 \pm 3.6$ & \\
\hline
\end{tabular}

*variables are analyzed by Mann-Whitney U test and shown as a median (interquartile range). RSWA: REM sleep without atonia, RBD: REM sleep behavior disorder, REM: rapid eye movement, PSM: propensity score matching

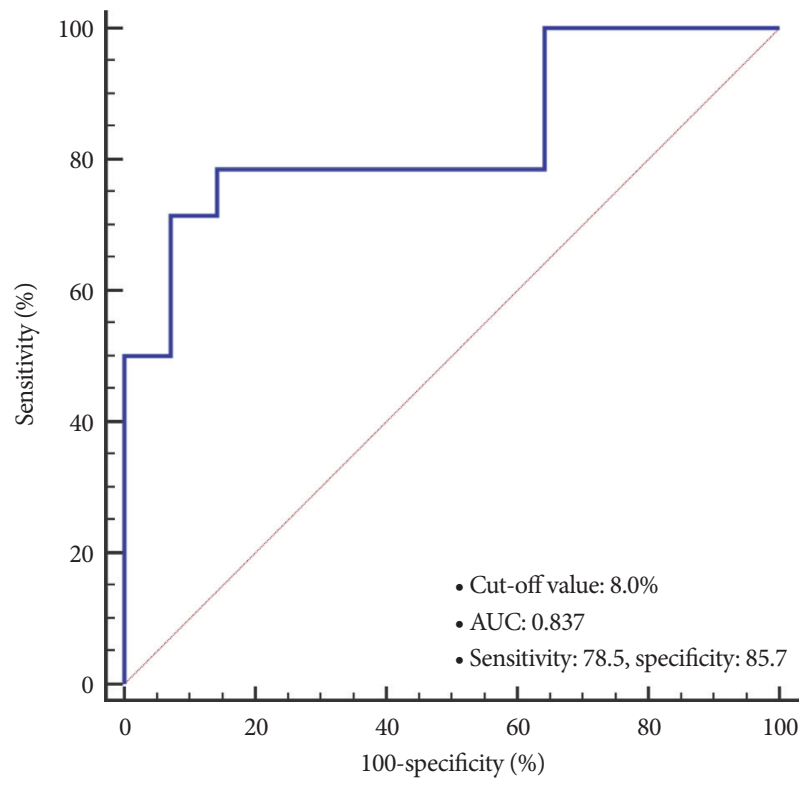

Figure 1. REM sleep without atonia and receiver operating characteristic curve in diagnosis of REM sleep behavior disorder. REM: rapid eye movement, AUC: area under the curve.

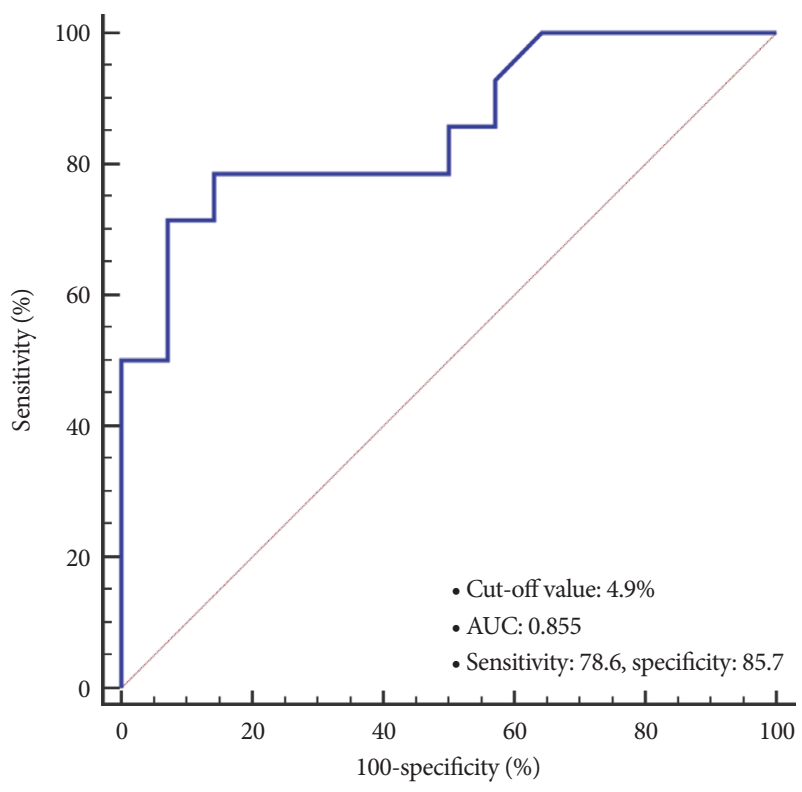

Figure 2. Tonic activity and receiver operating characteristic curve in diagnosis of rapid eye movement sleep behavior disorder. AUC: area under the curve. 


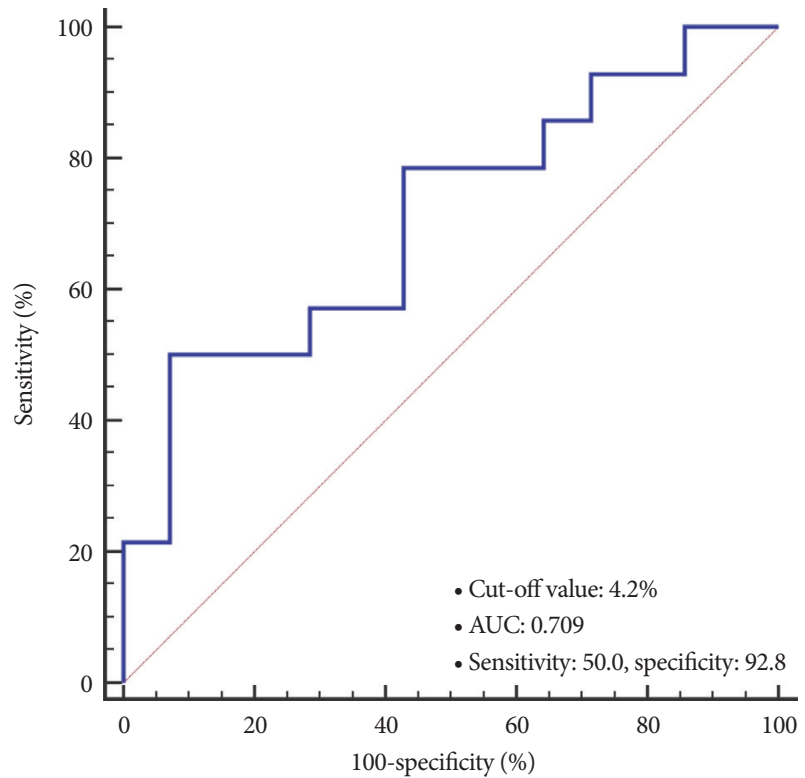

Figure 3. Phasic activity and receiver operating characteristic curve in diagnosis of rapid eye movement sleep behavior disorder. AUC: area under the curve.

면무긴장소실 에포크 비율 중위값은 $16.5 \%$ (사분위 간 범위, 8.8 24.6; 평균 \pm 표준편차, 20.8 \pm 16.5 )였으며, 렘수면행동 장애 진단을 위한 판정 기준값은 $8.0 \%$ (곡선 아래 면적 0.837 , 민감도 $78.5 \%$, 특이도 $85.7 \%$ )였다.

기존 연구들에서 렘수면무긴장소실 판정 기준값은 다양하 게 제시되고 있다. 국외의 연구 중 17 명의 렘수면행동장애군 과 6명의 대조군을 대상으로 한 연구에서는 $10 \%$ 이상의 렘 수면무긴장소실을 적절한 판정 기준값으로 제시하였다. ${ }^{17}$ 또 한 80명의 렘수면행동장애와 80명의 대조군을 비교한 연구 에서는 턱근전도에서 긴장성 움직임이 $30 \%$ 이상인 경우를 판정 기준값으로 했을 때 민감도 $73.8 \%$, 특이도 $90.0 \%$ 를 보 였고, 턱근전도에서 위상성 움직임을 $15 \%$ 이상으로 하였을 때는 민감도 $80.0 \%$, 특이도 $87.5 \%$ 로 보고하였다. ${ }^{18}$ 렘수면행 동장애와 기면병 및 대조군을 대상으로 실시한 연구에서는 렘수면행동장애와 대조군을 분류하는 판정 기준값으로 턱근 전도에서 긴장성 움직임이 $3.17 \%$ 이상인 경우 민감도 $87.0 \%$, 특이도 $100.0 \%$ 로 보고하였고, 턱근전도에서 위상성 움직임 을 $1.22 \%$ 이상을 기준으로 하였을 때 민감도 $100.0 \%$, 특이도 $100.0 \%$ 로 보고하였다. 그러나 앞서 설명한 국외 연구 중 마 지막 두 연구는 에포크 기준을 20초, 미니 에포크의 기준은 2 초로 정의하여 현재 주로 사용하는 한 에포크의 기준 30 초, 미니 에포크 3 초와는 다른 기준을 사용하였다. ${ }^{19}$

국내의 경우도 렘수면행동장애 진단을 위한 렘수면무긴장 소실 판정 기준에 대한 선행연구들이 있다. 렘수면행동장애 로 진단된 31명과 연령을 맞춘 31명의 대조군을 대상으로 실
시한 연구에서는 렘수면무긴장소실의 분포가 렘수면행동장 애군은 5.2 38.2\%였으며, 대조군의 경우 0.0 2.3\%를 보이고 있어 렘수면무긴장소실이 $5 \%$ 이상일 때 진단 기준으로 고려 해 볼 수 있다는 의견을 제시하였다..$^{14}$ 또한 40 명의 렘수면행 동장애군과 연령 및 성별을 맞춘 10 명의 대조군을 대상으로 한 연구에서는 전체 렘수면 시간을 기준으로 하는 경우 렘수 면무긴장소실의 판정 기준값을 $4.1 \%$, 에포크를 기준으로 하 는 경우 $6.1 \%$ 로 제시하였다. ${ }^{15}$ 마지막으로 17 명의 렘수면행 동장애군과 연령 및 성별을 맞춘 15 명의 대조군을 대상으로 실시한 연구에서는 렘수면무긴장소실 비율을 $6.5 \%$ 로 제시 하였다. ${ }^{20}$ 앞서 소개한 국내 연구의 경우도 먼저 소개한 두 개의 연구는 턱과 앞쪽 정강근육에서 무긴장의 소실을 측정 하였고, 마지막 연구의 경우 턱근전도에서만 무긴장의 소실 을 측정한 차이점이 있다.

본 연구에서 렘수면무긴장소실 판정 기준값은 $8.0 \%$ 로 $10 \%$ 이상의 판정 기준값을 제시한 일부 국외 연구와 비교하여 낮 은 값이지만, 국내에서 실시된 다른 연구결과인 5.0 6.5\% 범 위의 판정 기준값과는 유사한 결과를 보였다. 국내에서 실시 된 연구결과가 일부 해외 연구와 차이를 보이는 이유로 인 종에 따른 렘수면무긴장소실 발생의 정도 차이를 고려해 볼 수 있으나, 이에 대한 결론을 내리기에는 연구결과가 충분하 지 않다. 아시아에서 실시된 연구 중 렘수면무긴장소실 판정 기준값을 제시하지는 않았으나, 렘수면행동장애에서 렘수 면무긴장소실 발생 비율을 $40.7 \pm 25.5 \%$ (평균 \pm 표준편차)로 보고한 연구가 있으며, 이는 본 연구의 결과(20.8 \pm 16.5$)$ 보다 높은 수치를 보이고 있어 아시아인에서 렘수면무긴장소실 의 발생 정도가 다른 인종에 비하여 낮다고 단정 지을 수는 없다. ${ }^{21}$

Lapierre와 Montplaisir에 의해 렘수면무긴장소실에 대한 정량적인 평가 방법이 제안된 이후 렘수면무긴장소실에 대 한 최근 연구 경향은 컴퓨터를 이용한(computer-assisted method) 렘수면무긴장소실의 정량화가 시도되고 있다..$^{10}$ 컴 퓨터를 이용한 무긴장소실의 평가는 기존의 도수적 방법을 이용한 렘수면무긴장소실의 계산이 많은 시간이 소요되고 판독자마다 차이를 보일 수 있어 이를 극복하기 위하여 시도 되고 있다. Burns 등에 의하여 컴퓨터를 이용한 방법이 제시 되었고, ${ }^{22}$ 이를 Lapierre와 Montplaisir에 의해 실시된 도수적 방법과 비교하였을 때 긴장성 및 위상성 움직임에서 유의한 상관관계를 보여주었다. ${ }^{23}$ 그러나 컴퓨터를 이용한 방법도 각 연구자마다 렘수면무긴장소실 평가에 대한 알고리듬의 차이가 있어 임상에서 실제 사용되기 전 타당화 연구가 더 필요하다. ${ }^{23}$

본 연구의 제한점은 다음과 같다. 첫째, 렘수면무긴장소실 
평가 시 양측 상지근전도를 추가해서 평가하지 않았다. 양측 상지근전도를 추가해서 평가하는 경우 렘수면무긴장소실을 보다 정확히 평가할 수 있다고 알려져 있고, 이는 렘수면무 긴장소실의 정량화 결과값에 영향을 미칠 수도 있다. ${ }^{1}$ 향후 연구에서는 양측 상지근전도 추가 전후에 렘수면무긴장소실 의 정도 차이에 대한 평가도 필요하다. 둘째, 본 연구는 단면 연구이며 수면다원검사 시 사건수면을 보이지 않았던 이들 을 대조군으로 포함하였다. 그러나 향후 이들이 렘수면행동 장애를 보일지에 대한 확인이 필요하다. 즉 대조군으로 포함 된 이들이 향후 렘수면행동장애 증상을 보일지 혹은 대조군 에 지속적으로 포함이 될지에 대한 추적이 필요하다. 이와 같은 제한점에도 불구하고 본 연구는 몇 가지 장점이 있다. 첫째, 환자 대조군 설정 시 성향점수 짝짓기를 이용하여 후 향적 연구에서 결과에 영향을 줄 수 있는 선택 편견을 줄였 다. 둘째, 렘수면무긴장소실 정량화 시 평가자 간의 일치도 를 확인하고 평가를 진행하였다. 셋째, 렘수면행동장애 진단 을 위한 렘수면무긴장소실의 정량적 수치에 대한 일치된 의 견이 없는 상황에서 본 연구를 통하여 이에 대한 결과를 확 인할 수 있었다.

본 연구에서 렘수면행동장애군은 대조군에 비하여 렘수면 무긴장소실이 유의하게 증가되어 있었고, 렘수면행동장애 진단을 위한 렘수면무긴장소실 판정 기준값은 $8.0 \%$ 임을 확 인하였다. 또한 렘수면행동장애 진단을 위한 렘수면무긴장 소실 판정 기준값을 확립하기 위해서는 연구자마다 일치된 방법을 이용하여 연구가 이루어져야 할 것으로 생각한다.

\section{Acknowledgments}

This work was supported by a 2-Year Research Grant of Pusan National University.

\section{Conflicts of Interest}

The authors have no potential conflicts of interest to disclose.

\section{ORCID iDs}

Jiyoung Kim Gha-Hyun Lee Sang Min Sung Taewoong Kim Dae Soo Jung

\section{Author Contributions}

Conceptualization: Jiyoung Kim. Data curation: Jiyoung Kim, Taewoong Kim. Formal analysis: Jiyoung Kim. Funding acquisition: Dae Soo Jung. Investigation: Jiyoung Kim. Methodology: Jiyoung Kim. Writing—original draft: Jiyoung Kim. Writing_review \& editing: Jiyoung Kim, Gha-Hyun Kim, Sang Min Sung, Taewoong Kim, Dae Soo Jung.

\section{REFERENCES}

1. Sateia MJ. International classification of sleep disorders-third edition: highlights and modifications. Chest 2014;146:1387-1394.

2. Chase MH, Morales FR. The atonia and myoclonia of active (REM) sleep. Annu Rev Psychol 1990;41:557-584.

3. Schenck CH, Bundlie SR, Ettinger MG, Mahowald MW. Chronic behavioral disorders of human REM sleep: a new category of parasomnia. Sleep 1986;9:293-308.

4. Ohayon MM, Caulet M, Priest RG. Violent behavior during sleep. $J$ Clin Psychiatry 1997;58:369-376; quiz 377.

5. Chiu HF, Wing YK, Lam LC, et al. Sleep-related injury in the elderly-an epidemiological study in Hong Kong. Sleep 2000;23:513-517.

6. Rodriguez CL, Jaimchariyatam N, Budur K. Rapid eye movement sleep behavior disorder: a review of the literature and update on current concepts. Chest 2017;152:650-662.

7. Uchiyama M, Isse K, Tanaka K, et al. Incidental Lewy body disease in a patient with REM sleep behavior disorder. Neurology 1995;45:709-712.

8. Boeve BF, Silber MH, Saper CB, et al. Pathophysiology of REM sleep behaviour disorder and relevance to neurodegenerative disease. Brain 2007;130:2770-2788.

9. Galbiati A, Verga L, Giora E, Zucconi M, Ferini-Strambi L. The risk of neurodegeneration in REM sleep behavior disorder: a systematic review and meta-analysis of longitudinal studies. Sleep Med Rev 2019;43: 37-46.

10. Lapierre O, Montplaisir J. Polysomnographic features of REM sleep behavior disorder: development of a scoring method. Neurology 1992; 42:1371-1374.

11. Neikrug AB, Ancoli-Israel S. Diagnostic tools for REM sleep behavior disorder. Sleep Med Rev 2012;16:415-429.

12. You S, Jeon SM, Cho YW. Rapid eye movement sleep behavior disorder. J Sleep Med 2018;15:1-7.

13. Berry RB, Brooks R, Gamaldo CE, et al. The AASM manual for the scoring of sleep and associated events: rules, terminology and technical specifications: version 2.3. Darien: American Academy of Sleep Medicine, 2016.

14. Park SG, Shin DJ, Park HM, Lee YB, Shin DH, Park KH. Diagnostic approach with quantitative analysis of polysomnography in REM sleep behavior disorder. J Korean Sleep Res Soc 2012;9:46-51.

15. Lee JH, Jung YJ, Cha HK, Rhee HY, Choi HY, Shin WC. Quantification of REM sleep without atonia in Korean REM sleep behavior disorder patients: comparison of manual and computer-assisted scoring methods. J Korean Sleep Res Soc 2014;11:50-56.

16. Park CU, Kim HJ. Measurement of inter-rater reliability in systematic review. Hanyang Med Rev 2015;35:44-49.

17. Consens FB, Chervin RD, Koeppe RA, et al. Validation of a polysomnographic score for REM sleep behavior disorder. Sleep 2005;28:993997.

18. Montplaisir J, Gagnon JF, Fantini ML, et al. Polysomnographic diagnosis of idiopathic REM sleep behavior disorder. Mov Disord 2010;25: 2044-2051.

19. Khalil A, Wright MA, Walker MC, Eriksson SH. Loss of rapid eye movement sleep atonia in patients with REM sleep behavioral disorder, narcolepsy, and isolated loss of REM atonia. J Clin Sleep Med 2013; 9:1039-1048.

20. Lee SA, Kim CS, Cho CU, Kim B, Lee GH. Quantitative EMG criteria for diagnosing idiopathic REM sleep behavior disorder. Sleep Breath 2015;19:685-691.

21. Lin FC, Lai CL, Huang P, Liu CK, Hsu CY. The rapid-eye-movement sleep behavior disorder in Chinese-Taiwanese patients. Psychiatry Clin Neurosci 2009;63:557-562.

22. Burns JW, Consens FB, Little RJ, Angell KJ, Gilman S, Chervin RD. EMG variance during polysomnography as an assessment for REM sleep behavior disorder. Sleep 2007;30:1771-1778.

23. Fulda S, Plazzi G, Ferri R. Scoring atonia during normal and pathological rapid eye movement sleep: visual and automatic quantification methods. Sleep Biol Rhythms 2013;11:40-51. 